\title{
Personality factors in recently diagnosed multiple sclerosis patients: a preliminary investigation with the NEO-FFI scale
}

Fatores de personalidade em pacientes com diagnóstico recente de esclerose múltipla: uma investigação preliminar com a escala NEO-FFI

Aline Braz de Lima, Renata Alves Paes, Regina Maria Papais Alvarenga

\begin{abstract}
This article describes some prevalent personality dimensions of recently diagnosed multiple sclerosis patients. A sample of 33 female recently diagnosed with relapsing-remitting multiple sclerosis (RRMS) was assessed with the NEO-FFI personality scale. Beck depression $(\mathrm{BDI})$ and anxiety (BAI) scales were also used. No significant levels of anxiety or depression were identified in this group. As for personality factors, conscientiousness was the most common factor found, whereas openness to experience was the least observed. Literature on the relationship between personality and MS is scarce and there are no Brazilian studies on this subject. Some personality traits might complicate or facilitate the experience of living with a chronic, disabling and uncertain neurological condition such as MS.
\end{abstract}

Keywords: multiple sclerosis, personality, NEO-FFI.

\section{RESUMO}

Este artigo descreve alguns traços prevalentes de personalidade em pacientes com esclerose múltipla recém-diagnosticada. Uma amostra de 33 mulheres recentemente diagnosticadas com a forma clínica remitente-recorrente da esclerose múltipla (EMRR) foi avaliada com a escala de personalidade NEO-FFI. As escalas de Beck de depressão e de ansiedade também foram usadas. Não foram identificados níveis significativos de ansiedade ou depressão neste grupo. Em relação aos fatores de personalidade, a conscienciosidade se mostrou como o traço mais prevalente, enquanto a abertura à experiência foi o menos observado nesta amostra. A literatura acerca desta relação esclerose múltipla-personalidade é pouco expressiva e não há estudos brasileiros sobre este tema. Acredita-se que alguns traços de personalidade possam dificultar ou facilitar a experiência de estar vivendo com uma condição neurológica crônica, incapacitante e de curso incerto como a esclerose múltipla.

Palavras-chave: esclerose múltipla, personalidade, NEO-FFI.

Traditionally, most studies on psychological aspects of neurological diseases focus cognitive and psychiatric changes. On the other hand, other important aspects also related to the patient are rather scarce. Therefore, studies on personality characteristics associated with neurological conditions are unusual ${ }^{1}$.

Personality consists of stable characteristics that make behavior consistent over time. It is what makes us unique $^{2}$. Despite the fact that our personality changes for the better with age - according to the American Psychological Association (APA) - living with a disabling and chronic disease might affect this consistency over time. Thus, misfortune in general may play a significant role in one's personality. Accordingly, most authors agree that personality characteristics might affect psychological functioning while the patient is adjusting to a chronic disease $e^{3,4,5,6}$.

\section{LIVING WITH MULTIPLE SCLEROSIS (MS)}

MS is an inflammatory demyelinating disease of the central nervous system (CNS). Relapses can be recurrent. The clinical course of MS is uncertain. In general, after relapses, which may last days, weeks or even months ${ }^{1}$, some patients recover completely and go back to living a normal life. For others, though, the course of this disease can be progressive throughout the years.

Universidade Federal do Estado do Rio de Janeiro, Hospital Universitário Gafrée \& Guinle, Divisão de Neurologia, Rio de Janeiro RJ, Brazil. Correspondence: Aline Braz de Lima; Avenida Augusto Severo, 132/302; 20021-040 Rio de Janeiro RJ, Brasil; E-mail:alinebrazdelima@gmail.com Conflict of interest: There is no conflict of interest to declare.

Received 15 May 2014; Received in final form 31 October 2014; Accepted 19 November 2014. 
Usually the first MS relapse can happen within an age range that goes from 18 to 55 years, although it occurs more frequently among people with 20 to 40 years of age, according to clinical criteria ${ }^{3}$. These patients are usually studying, starting or developing a career and/or starting a family. They are struggling to gain social responsibility and financial independence ${ }^{4}$. Uncertainty in MS relapses and progress of the disease can threaten life projects. Eventually, getting acquainted with personality traits of MS patients is a useful piece of information, because they help understand how they cope with MS. This knowledge adds value to therapeutic approach and treatment ${ }^{5}$. For instance, a recent study investigated employment status of MS patients and its relationship with their personality characteristics ${ }^{6}$. Persistence was the trait strongly related with employability.

MS patients often experience apprehension on a daily basis through the possibility of relapses. They even take a careful lifestyle because they do not know if or when a new relapse might occur. Thus, living with MS for many patients can become a tough challenge.

While in the past most studies used the Minnesota Multiphasic Personality Inventory (MMPI), a personality inventory designed to identify psychiatric disorders; currently, the Five Factor Model (FFM) is the most popular, empirically supported and scientifically useful personality taxonomy. The FFM personality measure that received the most empirical attention is the NEO-PI, which has a revised version (NEO PI-R) as well as a shorter version, the NEO-FFI (NEO five Factor Inventory) ${ }^{7}$. This tool has been validated and used extensively in cross-cultural studies. Preliminary use of the NEO-FFI scales in MS has revealed associations between personality and chronic fatigue and depression ${ }^{8}$.

This model is a comprehensive description of the basic personality structure. The five major personality dimensions of personality are: Neuroticism (N), Extraversion (E), Openness to Experience (O), Agreeableness (A) and Conscientiousness $(\mathrm{C})^{7}$. The FFM was developed from the lexical approach of the personality structure. Such approach is based on factor analyses of trait terms commonly and widely used by people to describe themselves and others, derived from the English language dictionaries ${ }^{8}$. The central hypothesis of the lexical approach is that important personality traits are encoded in natural language ${ }^{9}$.

Neuroticism, for instance, is a tendency to experience negative emotions, such as hostility, anger and sadness. Extraversion describes an outgoing and sociable nature. A person who is open to experience is generally curious, imaginative and seeks novelty. Agreeableness is a tendency to cooperate rather than compete. Finally, conscientiousness means lack of impulsivity, tidiness and a goal-oriented mind.

The commercially available tool designed to assess FFM dimensions is the Revised NEO Personality Inventory or NEO-PI-R, developed by Paul Costa and Robert McCrae launched in 1992. In Brazil, this personality scale was validated for the Brazilian population by Carmen Flores-Mendoza in 2007.

This inventory has already been used in some studies with MS patients. In 2011, an important study with 419 MS patients was published. The authors wanted to determine if the NEO-FFI was a reliable and valid assessment tool. They found adequate estimates of internal consistency, factorial validity, and self-informant correlation that supported its use with this population ${ }^{10,11}$.

Significant psychological distress is commonly seen in MS patients. This study is a preliminary investigation of personality traits and multiple sclerosis in Brazil. We have examined the frequency distribution of 5 personality dimensions in recently diagnosed relapsing-remitting multiple sclerosis (RRMS) patients, using the shortened version of the NEO-PI personality inventory, the NEO-FFI.

\section{METHOD}

\section{Participants}

This preliminary study had a cross-sectional, observational and descriptive design. The subjects came from the outpatient Neurology service of the university hospital HUGG (Hospital Universitário Gaffree \& Guinle). They were diagnosed with definite MS by their neurologists ${ }^{12}$ and then invited by the latter to take part in this study, respecting inclusion/exclusion criteria. Patients with other neurological diseases or other neurofunctional disturbances, a history of psychiatric conditions, with past or current drug abuse prior to MS onset, head trauma, significant depression and/or anxiety levels and visual/auditory deficits that could interfere in the performance of the tests were excluded. All patients presented a low Expanded Disability Status Scale (EDSS) ( $\leq 3.5)$ and had their first relapse within 2 months to 3 years before the assessment. The inclusion criteria were used to reduce confounds resulting from interactions between personality traits and other aspects such as previous psychological co morbidities or/and motor impairment that would change the patients' lifestyle. This data collection at one specific point in time attempted to assess patients' personality traits free from major confounding factors.

Our convenience sample of MS patients initially consisted of $40 \mathrm{MS}$ patients. After assessing this group, there were only 7 (seven) men. Due to the very small number of male subjects in this study, the authors decided to remove this group from statistical analysis. They have not considered this number representative in order to make significant inferences. The 33 female MS patients remained. All patients came from the outpatient neurology clinic of the university hospital, respecting exclusion and inclusion criteria. All patients gave informed consent to take part in this study. 
Table 1. Descriptive analysis of general data - clinical and demographic - 33 recently diagnosed female relapsing-remitting multiple sclerosis (RRMS) patients.

\begin{tabular}{|c|c|c|c|c|c|}
\hline Variable & Minimum & Maximum & Mean & SD & Median \\
\hline Age & 21 & 57 & 36.96 & 9.57 & \\
\hline Educational level & 9 & 24 & 15.86 & 3.90 & \\
\hline EDSS & 0 & 3.5 & - & - & 1.5 \\
\hline Length of disease (months) & 2 & 36 & 21.09 & 12.35 & \\
\hline
\end{tabular}

EDSS: Expanded Disability Status Scale; SD: Standard deviation.

This study was approved by the Ethical Committee of Gafree \& Guinle University Hospital.

\section{Instruments}

Patients went through a semi-structured interview in order to provide clinical and demographic information. Then, they received the NEO-FFI inventory. This personality scale is a 60-item self-report questionnaire answered on a five-point Likert scale, which ranges from strongly agree (1) to strongly disagree (5). Participants were tested by the same psychologist. A parallel study that assessed cognitive changes in early MS used Beck inventories for anxiety (BAI) and depression (BDI) in the same group. Those scores were used in this study. Moreover, the purpose of this study was not to assess cognitive aspects in MS. However, the same MS group used in the present study also went through neuropsychological assessment - through a brief neuropsychological battery - in an ongoing investigation on cognition in recent MS.

\section{Neuropsychological Assessment}

The brief neuropsychological assessment battery applied in the same group of MS patients on a parallel ongoing study was previously used by Paes $^{13}$ and Rodrigues et al. ${ }^{14}$. This battery focused tests with higher sensitivity and specificity, according to Negreiros et al. ${ }^{15}$ and Paes et al. ${ }^{16}$. The tests were: (a) Rey Auditory Verbal Learning Test (RAVLT); (b) Digit Symbol Modalities Test (SDMT); (c) Hooper Visual
Organization Test (HVOT); and (d) Controlled Oral Word Association Test (COWAT).

\section{RESULTS}

Demographic data of this sample of MS patients is shown in Table 1. The mean age of this group was congruent with MS profile and with data found in other studies (36.96 years). Educational level was rather high due to the social environment of this group (15.86 years), which was the metropolitan area of Rio de Janeiro. The EDSS scores were expectedly low, according to inclusion criteria. (Median $=1.5$ ) with minimum score of 0 and maximum of 3.5. The 33 women of this sample were not impaired. Mean length of the disease was 21.09 months, in order to set the MS recent status. Patients did not present significant levels of anxiety and depression, minimizing the risk of psychiatric co-morbidity (a confounding variable in personality assessment) (Table 2). Frequency distribution and percentages of the five dimensions scored by NEO-FFI found in the sample are presented in Table 3 and in Figure.

\section{DISCUSSION}

This study investigated personality factors of recently diagnosed MS patients using NEO-FFI, a scale based on

Table 2. Descriptive analysis of scores and means of Beck scales for anxiety (BAI) and depression (BDI) ( $N=33)$. Data borrowed from the study on cognition in recent RRMS.

\begin{tabular}{lcccc}
\hline Anxiety/depression & Minimum & Maximum & Mean & SD \\
\hline BAl & 0 & 32 & 10.8 & 10.6 \\
BDI & 0 & 29 & 9.1 & 7.3 \\
\hline
\end{tabular}

SD: Standard deviation.

Table 3. Frequency distribution of the 5 factors of personality assessed by NEO-FFI in the sample with 33 female relapsingremitting multiple sclerosis (RRMS) patients classified by percentile.

\begin{tabular}{|c|c|c|c|c|c|}
\hline Factors/classification & Very low & Low & Medium & High & Very high \\
\hline Neuroticism & 21.2 & 9.1 & 36.4 & 27.3 & 6.1 \\
\hline Extaversion & 15.2 & 27.3 & 27.3 & 24.2 & 6.1 \\
\hline Openness to experience & 18.2 & 33.3 & 36.4 & 9.1 & 3.0 \\
\hline Agreeableness & - & 27.3 & 24.2 & 30.3 & 18.2 \\
\hline Conscientiousness & 3.0 & 18.2 & 27.3 & 42.4 & 9.1 \\
\hline
\end{tabular}




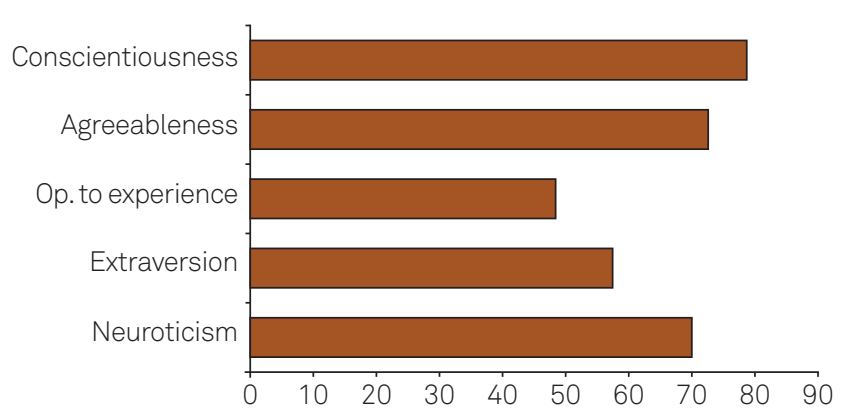

Op: openess.

Figure. Accumulated frequency of NEO-FFI in 33 recentlydiagnosed relapsing-remitting multiple sclerosis (RRMS) female patients.

the FFM of the personality, also known as the Big Five. The most frequent dimensions seen in this group were: conscientiousness, agreeableness and neuroticism. Bruce and colleagues studied the association between personality factors (assessed by NEO-FFI) and adherence to treatment, with a predominantly feminine sample of RRMS patients ${ }^{17}$. Their findings showed that patients with good adherence also presented high levels of agreeableness, consciousness and neuroticism.

Conscientiousness obtained the highest frequency, which means that these patients lack impulsivity. Hawkes, in 2005, however, found a rather different result while examining impulsiveness or risk-disregarding behavior in MS patients. Smoking, alcohol consumption and high cholesterol were some of the variables considered. According to this study, MS patients neglected healthy behaviors compared to healthy controls ${ }^{18}$. Another study of 2013 found similar results as to low conscientiousness in MS patients. The authors parted from the hypothesis that personality plays a role on the relationship between brain volume and cognitive/neuropsychiatric MS features. For instance, patients with low conscientiousness were at a higher risk for developing MS-associated neuropsychiatric symptoms ${ }^{19}$.

Agreeableness was the second trait most frequently seen in this group. Agreeable people are more cooperative than competitive. On the other hand, agreeableness also means vulnerability in competitive settings. Other studies on personality of MS patients found a similar pattern ${ }^{1,20,21}$. An avoidant personality style was identified in this group of MS patients. In general, agreeable people can have low self esteem, if this trait is due to confrontation avoidance. Moreover, it increases the fatigue sensation ${ }^{21}$. The avoidant personality style is also associated with poor problem-solving strategies ${ }^{22,23,24}$.
Neuroticism seems to be the personality dimension that most interferes with adjustment to disease. The present study showed neuroticism as a common trait among our MS patients group. McCray and colleagues presented interesting aspects of neuroticism, using the NEO-FFI. According to these authors, high levels of neuroticism were seen more often in depressed patients ${ }^{25}$. In the present group of MS patients, no clinical depression was detected. Beck scales for anxiety and depression have not shown consistent signs of either condition. Investigating personality during the initial stage of the disease enables us to witness a functional structure, struggling to adapt to MS. Early MS is more commonly related to signs of anxiety than depression ${ }^{26,27,28}$.

Clinical psychologists can notice in daily practice that neurotic people do not feel emotionally equipped to solve problems effectively. This perception was confirmed in a quite recent study published in 2010. The authors found out that neurotic individuals tend to feel more fatigued and also end up showing higher levels of inflammatory markers, such as interleukin 6 (IL-6) ${ }^{29}$. The latter aspect is considered a risk factor to the development of depression symptoms ${ }^{30}$.

Openness to experience (OE) rarely appeared as a significant trait when relationship of personality and disease is concerned. No study highlighted the importance of this particular dimension. OE is usually low in MS patients, what was confirmed in the present study. MS patients in this group were more conservative and traditional, not inclined to novelty. A high $\mathrm{OE}$ score is associated with flexibility, curiosity and preference for variety ${ }^{31}$.

It is also worth mentioning that a recent study used imaging ( $\mathrm{fMRI}$ ) of MS patients to have grounds to suggest that neural activity related to specific personality dimension is a preserved neurophysiologic characteristic in RRMS patients at an early stage of the disease ${ }^{32}$.

Early identification of certain personality traits could help care professionals in preventing or minimizing secondary neuropsychiatric disorders, such as anxiety and depression through providing early psychological support. A deeper understanding of this neurological disease could also shed some light to treatment adherence ${ }^{16}$.

This study had its limitations such as a small sample. It could be extended in time, through a longitudinal design and it could be applied to other clinical courses of MS. Multidisciplinary professional teams assisting MS patients could take into consideration their individual characteristics in adjusting to this chronic and impairing condition. Currently, many studies are pointing to the fact that it is no longer possible to underestimate the emerging role of personality in clinical neuroscience. 
1. Ozõura A, Erdberg P, Šega S. Personality characteristics of multiple sclerosis patients: a Rorschach investigation. Clin Neurol Neurosurg. 2010;112(7):629-32.

2. Pervin L, Oliver J. Personalidade: teoria e pesquisa. 8 a ed. Porto Alegre: Artmed; 2004.

3. Rätsep T, Kallasmaa T, Pulver A, Gross-Paju K. Personality as a predictor of coping efforts in patients with multiple sclerosis. Mult Scler. 2000;6(6):397-402. http://dx.doi.org/10.1177/ 135245850000600607

4. Bogle N, Percy M, Morrison W. Will I make it through this choppy water? a psychological characteristic as a predetermining factor to coping with multiple sclerosis. Axone. 1999;20(3):63-6.

5. Peyser JM, Edwards KR, Poser CM. Psychological profiles in patients with multiple sclerosis. A preliminary investigation. Arch Neurol. 1980;37(7):437-40. http://dx.doi.org/10.1001/archneur. 1980.00500560067009

6. Strober LB, Christodoulou C, Benedict RH, Westervelt HYJ, Melville P, Scherl WF. et al. Unemployment in multiple sclerosis: the contribution of personality and disease. Mult Scler. 2012;18(5):647-53. http://dx.doi.org/10.1177/1352458511426735

7. McCrae RR, John OP. An introduction to the five-factor model and its applications. J Pers. 1992;60(2):175-215.

8. Merkelbach S, König J, Sittinger $\mathrm{H}$. Personality traits in multiple sclerosis patients with and without fatigue experience. Acta Neurol Scand. 2003;107(3):195-201. http://dx.doi.org/10.1034/ j.1600-0404.2003.02037.x

9. Goldberg LR. An alternative "description of personality": the big-five factor structure. J Pers Soc Psychol. 1990;59(6):1216-29. http://dx. doi.org/10.1037/0022-3514.59.6.1216

10. Koroktov D, Hannah TE. the five-factor model of personality: strengths and limitations in predicting health status, sick-role and illness behavior. Pers Individ Dif. 2004;36(1):187-99. http://dx.doi.org/ 10.1016/S0191-8869(03)00078-3

11. Schwartz ES, Chapman BP, Duberstein PR, Weinstock-Guttman B, Benedict RH. The NEO-FFI in Multiple Sclerosis: internal consistency, factorial validity and correspondence between self and informant reports. Assessment. 2011;18(1):39-49. http://dx.doi.org/10.1177/ 1073191110368482

12. McDonald WI, Compston A, Edan G, Goodkin D, Hartung HP, Lublin FD et al. Recommended diagnostic criteria for multiple sclerosis: guidelines from the International Panel on the diagnosis of multiple sclerosis. Ann Neurol. 2001;50(1):121-7. http://dx.doi.org/10.1002/ana.1032

13. Paes RA. Frequency of cognitive changes in three courses of Multiple Sclerosis - Relapsing Remitting, Primary Progressive and Benign using a brief neuropsychological battery (BNB) [doctor's thesis]. Frequência de alterações cognitivas em três formas clínicas da Esclerose Múltipla - Remitente-Recorrente, Progressiva Primária e Benigna - usando uma bateria neuropsicológica breve. Rio de Janeiro: Universidade Federal do Rio de Janeiro; 2011.

14. Rodrigues DN, Paes RA, Vasconcelos CCF, Landeira-Fernandes J, Alvarenga RMP. Different cognitive profiles of Brazilian patients with relapsing-remitting and primary progressive multiple sclerosis. Arq Neuropsiquiatr. 2011;69(4):590-5. http://dx.doi.org/10.1590/ S0004-282X2011000500004

15. Negreiros MA, Mattos P, Landeira-Fernandez J, Paes RA, Alvarenga RP. A brief Neuropsychological screening test battery for cognitive dysfunction in Brazilian multiple sclerosis patients. Brain Inj. 2008;22(5):419-26. http://dx.doi.org/10.1080/02699050801998243

16. Paes RA, Alvarenga RMP, Vasconcelos CCF, Negreiros MA, LandeiraFernandez J. [Neuropsychology of primary progressive multiple sclerosis]. Rev Neurol. 2009;49(7):343-8. Spanish.
17. Bruce JM, Hancock LM, Arnett P, Lynch SG. Treatment adherence in multiple sclerosis: association with emotional status, personality and cognition. J Behav Med. 2010;33(3):219-27. http://dx.doi.org/10.1007/ s10865-010-9247-y

18. Hawkes $\mathrm{CH}$. Are multiple sclerosis patients risk-takers? QJM. 2005;98(12):895-911. http://dx.doi.org/10.1093/qjmed/hci135

19. Benedict RH, Schwartz CE, Duberstein P, Healy B, Hoogs M, Bergsland $\mathrm{M}$ et al. Influence of personality on the relationship between gray matter volume and neuropsychiatric symptoms in multiple sclerosis. Psychosom Med. 2013;75(3):253-61. http://dx.doi. org/10.1097/PSY.0b013e31828837cc

20. Lode K, Bru E, Klevan G, Myhr KM, Nyland H, Larsen JP. Coping with multiple sclerosis: a 5-year follow-up study. Acta Neurol Scand. 2010;122(5):336-42. http://dx.doi.org/10.1111/j.1600-0404. 2009.01313.x

21. Fragoso YD, Silva EO, Finkelsztejn A. Correlation between fatigue and self-esteem in patients with multiple sclerosis. Arq Neuropsiquiatr. 2009;67(3B):818-21. http://dx.doi.org/10.1590/ S0004-282X2009000500007

22. O'Brien MT. Multiple sclerosis: the relationship among self-esteem social support and coping behavior. Appl Nursing Res.1993;6(2):54-63. http://dx.doi.org/10.1016/S0897-1897(05)80103-X

23. McCabe MP, McKern S, McDonald E. Coping and psychological adjustment among people with multiple sclerosis. J Psychosom Res. 2004;56(3):355-61. http://dx.doi.org/10.1016/S0022-3999(03)00132-6

24. Goretti B, Portaccio E, Zipoli V, Hakiki B, Siracusa G, Sorbi S et al. Coping strategies, psychological variables and their relationship with quality of life in multiple sclerosis. Neurolog Sci. 2009;30(1):15-20. http://dx.doi.org/10.1007/s10072-008-0009-3

25. McCray LW, Bogner HR, Sammel MD, Gallo JJ. The role of patient personality in the identification of depression in older primary care patients. Int J Geriatr Psychiatry. 2007;22(11):1095-100. http://dx.doi. org/10.1002/gps.1791

26. Beiske AG, Svensson E; Sandanger I, Czujiko B, Pedersen ED, Aarseth $\mathrm{JH}$ et al. Depression and anxiety amongst multiple sclerosis patients. Eur J Neurology. 2008;15(3):239-45. http://dx.doi.org/10.1111/j.14681331.2007.02041.x

27. Potagas C, Mitsonis C, Watier L, Dellatolas G, Retziou A, Mitropoulos $P$ et al. Influence of anxiety and reported stressful life events on relapses in multiple sclerosis: a prospective study. Multiple Scler. 2008;14(9):1262-8. http://dx.doi.org/10.1177/1352458508095331

28. Mendes MF, Tilbery CP, Balsimelli S, Moreira MA, Barão-Cruz AM. Depression in relapsing remitting multiple sclerosis. Arq Neuropsiquiatr. 2003;61(3A):591-5. http://dx.doi.org/10.1590/S0004-282X2003000400012

29. Merkelbach S, König J, Sittinger $H$. Personality traits in multiple sclerosis patients with and without fatigue experience. Acta Neurol Scand. 2003;107(3):195-201. http://dx.doi.org/10.1034/j.1600-0404. 2003.02037.x

30. Sutin AR, Terraciano A, Deiana B, Naitza S, Ferruci L, Uda M et al. High neuroticism and low conscientiousness are associated with Interleukin-6. Psychol Med. 2010;40(9):1485-93. http://dx.doi.org/ 10.1017/S0033291709992029

31. Bruce JM, Lynch SG. Personality traits in multiple sclerosis: Association with mood and anxiety disorders. J Psychosom Res. 2011;70(5):479-85. http://dx.doi.org/10.1016/j.jpsychores.2010.12.010

32. Costa PT, McCrae RR. NEO PI-R: inventário de personalidade NEO revisado e inventário de cinco fatores. São Paulo: Vetor; 2007

33. Gioia MC, Cerasa A, Valentino P, Fera F, Nisticò R, Liguori M et al. Neurofunctional correlates of personality traits in relapsing-remitting multiple sclerosis: an fMRI study. Brain Cogn. 2009;71(3):320-27. http://dx.doi.org/10.1016/j.bandc.2009.07.009 